\title{
RELAÇÕES DE PODER E CONTROLE NA INDÚSTRIA AUTOMOBILISTICA
}

\author{
RELATIONS OF POWER AND CONTROL IN THE AUTOMOTIVE INDUSTRY
}

Recebido em 18.02.2015. Aprovado em 12.05.2015

Avaliado pelo sistema double blind review

DOI: http://dx.doi.org/10.12712/rpca.v9i2.537

\section{Pedro Luiz Maitan Filho}

maitan.pedro@gmail.com

Universidade Federal Rural do Rio de Janeiro, Seropédica/RJ, BRASIL

\author{
Janaina Machado Simoes \\ janainamsimoes@gmail.com \\ Universidade Federal Rural do Rio de Janeiro, Seropédica/RJ, BRASIL
}

\begin{abstract}
Resumo
A fragmentação da concorrência e a busca por resultados de curto prazo no contexto da indústria automotiva têm reforçado práticas organizacionais em prol da alta performance nos processos produtivos. Diante disso, a temática da alta produtividade tem ocupado um espaço cada vez mais significativo em discussões acerca das relações de trabalho estabelecidas no sistema industrial automotivo. Tendo isso em vista, esse artigo busca analisar de que maneira as relações de poder e controle tem se configurado na estrutura de trabalho dentro do setor de processos industriais da montadora ALFA. Este estudo foi conduzido a partir de entrevistas semiestruturadas realizadas com engenheiros na unidade produtiva do Grupo no Brasil. Os resultados da pesquisa de campo mostraram que a fragmentação do senso de coletividade na rotina industrial e o maior rigor na cobrança por resultados cada vez mais desafiadores têm acentuado a precarização das condições de vida dos trabalhadores.
\end{abstract}

Palavras-chave: Trabalho. Poder. Controle. Indústria automotiva.

\section{Abstract}

The fragmentation of competition and the search for short-term outcomes in the automotive industry have enhanced organizational practices on high performance in production processes. Therefore, the theme of high productivity has played an increasingly significant place in discussions about the working relationship established in the automotive industrial system. With this in mind, this article aims to analyze how the relations of power and control has been configured in the working structure within the industrial processes area of ALFA automaker. This study was conducted from semi-structured interviews with engineers in the Group's production unit in Brazil. Field survey results showed the fragmentation of the collective sense in industrial routine and the more rigorous accountability for challenging results have highlighted the precariousness of the living conditions of workers.

Keywords: Labor. Power. Control. Automotive industry. 


\section{Introdução}

A indústria automobilística tem se caracterizado como um ambiente marcado por mudanças nas relações de trabalho (RODRIGUES, 2002). Em um cenário de concorrência fragmentada, as montadoras procuram ajustar permanentemente os arranjos produtivos com novos modelos de organização dos profissionais empregados nas fábricas de veículos. Desta forma, essas estratégias têm impactado significativamente as configurações organizacionais e a realocação de recursos por meio de terceirizações, contratações temporárias e aplicação de tecnologias que visam a redução dos custos e encargos nos sistemas produtivos.

A trajetória destaindústria tem apresentado uma relação entre os modelos de produção e a mudanças do perfil funcional dos trabalhadores (CIMBALISTA, 2007). A estrutura tecnocrática fordista concebia um estilo de produção próximo ao artesanal e dependente das habilidades individuais da força de trabalho. O toyotismo (TENÓRIO, 2011), ampliou a operacionalização de métodos de trabalho multifuncionais e tecnológicos no sistema produtivo. Não obstante tal contribuição, esta conjuntura acabou gerando no contexto automotivo relações mais inseguras de emprego e, nas últimas décadas, uma tendência à deterioração das condições do trabalho industrial (LEITE, 2004).

Em busca de maior flexibilidade produtiva e maximização da produtividade, contrasta hoje com os métodos sofisticados das montadoras, a perda deste senso de perenidade das relações de trabalho (PATIAS, BELATO e OLEA, 2008). Assim, as discussões apresentadas aqui buscaram problematizar como essa redefinição do protagonismo humano no sistema automotivo (KINDI, 2013) tem interferido em questões como a competição interna e a individualidade (HOPFER e FARIA, 2006), os novos mecanismos de poder (PAGÈS et al, 1987), as práticas de controle sobre o trabalho (FARIA e RAMOS, 2012) e precarização das condições de vida das pessoas (ANTUNES, 2005).

Em um período de escassez de novas vagas e de maiores exigências quanto ao perfil profissional, pôde ser levantado nesta pesquisa um material empírico acerca das relações de poder dentro dos processos industriais automotivos. A partir da investigação na montadora escolhida, o estudo reforça a tese da produção de subjetividades em bases cada vez mais ideológicas, dos objetivos conflitantes no trabalho e das disputas internas entre os pares funcionais.
Um cenário este caracterizado por uma estrutura de poder mantida pelo poder financeiro das empresas. A imposição das práticas de trabalho baseadas no relacionamento interpessoal tem resultado, desta forma, em normas muitas vezes obscuras e estranhas aos trabalhadores.

Essas questões aparecem no Grupo automotivo ALFA, sobretudo no decorrer das mudanças ocorridas nos últimos cinco anos em uma unidade brasileira. A fim de aumentar a velocidade no lançamento dos veículos, essa empresa passou a se estruturar por equipes temporárias, mantidas por contratos de curto prazo - segundo a vigência dos projetos de novos veículos. A partir das falas dos trabalhadores, o presente artigo busca mostrar de que maneira as relações de poder e controle tem se configurado dentro do setor de processos industriais da montadora ALFA. Nesta perspectiva, a pesquisa também busca contribuir com as discussões acerca dos dilemas enfrentados na gestão de empresas cada vez mais complexas. Em última instância, o artigo pretende suscitar reflexões sobre as diferentes formas de precarização do trabalho nas organizações modernas.

\section{As discussões teóricas sobre poder e controle na indústria}

Segundo os autores citados neste artigo, há um processo de transição na configuração laboral estabelecida na rotina das organizações. Questões estas referentes à maneira como a evolução dos processos de produção e a concentração do capital em grandes empresas agregaram ao trabalho outros aspectos além de uma concepção puramente mecânica.

\section{Panorama sucinto da indústria automobilística no Brasil}

Muitos foram os eventos que marcaram a trajetória da indústria automobilística brasileira. Coelho (2012) apresentou o histórico desse segmento industrial por meio de quatro períodos principais, conforme o quadro a seguir: 
Quadro 1 - A indústria automobilística brasileira

\begin{tabular}{|c|l|}
\hline \multicolumn{1}{|c|}{ Período } & \multicolumn{1}{c|}{ Fatos históricos } \\
\hline Anos 1900 - 1930 & $\begin{array}{l}\text { Empresas como Grassi, Ford e GM } \\
\text { iniciam atividades no Brasil como } \\
\text { importadores de autopeças. }\end{array}$ \\
\hline Anos 1940 - 1960 & $\begin{array}{l}\text { O Brasil se destaca entre os } \\
\text { importadores de veículos, } \\
\text { gerando investimentos em } \\
\text { fabricação de autopeças. Surgem } \\
\text { as primeiras fábricas de veículos } \\
\text { em São Paulo (Volkwagen e } \\
\text { Mercedez). O presidente Juscelino } \\
\text { Kubitschek anuncia a criação do } \\
\text { Grupo Executivo da Indústria } \\
\text { Automobilística (GEIA) no Brasil. }\end{array}$ \\
\hline Anos 1960 - 1990 & $\begin{array}{l}\text { O país se torna o nono maior } \\
\text { produtor mundial de automóveis. } \\
\text { Começa a produção em massa } \\
\text { dos carros populares (de 1000 } \\
\text { cilindradas). Período de formação de } \\
\text { preços competitivos aos automóveis } \\
\text { importados e incentivos fiscais. }\end{array}$ \\
\hline A partir dos anos & $\begin{array}{l}\text { Nova reestruturação do setor } \\
\text { automotivo no Brasil. Construção } \\
\text { de fábricas mais modernas para } \\
\text { competir no Mercosul. Início } \\
\text { da desverticalização da cadeia } \\
\text { produtiva e ampliação da integração } \\
\text { montadoras-autopeças e montadoras- } \\
\text { fornecedores. }\end{array}$ \\
\hline E90
\end{tabular}

Fonte: Adaptado de Coelho (2002), p.53-54

Sobre a trajetória histórica das montadoras de veículos no país, Botelho (2002) comenta que este foi um dos setores industriais que mais se beneficiou com as políticas econômicas entre os anos de 1950 e 1990. As transformações ocorridas no setor automotivo a partir de então, ainda segundo este autor, tiveram relação importante com o processo de abertura econômica - também identificado como o período de internacionalização da indústria automobilística. A expansão das montadoras em uma conjuntura de abertura econômica passou então a ser analisada pelos pesquisadores em duas perspectivas: a primária, sob o ponto de vista das matrizes; e a secundária, no âmbito das subsidiárias instaladas no Brasil (COELHO, 2012).

Do ponto de vista externo, os analistas do setor automotivo buscaram enfocar o ambiente de oportunidades que as matrizes norte-americanas e europeias encontraram para desconcentrar a produção em regiões com menor participação no uso de automóveis (ARBIX, 2002). Pela via secundária, esse período foi legitimado internamente por políticas articuladas em torno do Regime Automotivo Brasileiro (RAB), inaugurado no governo de Fernando Henrique Cardoso (COELHO, 2012). A ampliação de ofertas para os chamados newcomers objetivou, neste caso, modernizar o setor automotivo para, num segundo passo, usar montadoras como ferramentas para a captação de investimentos externos (ARBIX, 2002).

Em relatório anual veiculado pelo Banco Nacional de Desenvolvimento Econômico e Social (BNDES), Barros e Pedro (2011) assinalaram que até a abertura comercial ocorrida no início da década de 1990, a produção automotiva se concentrava nos Estados de São Paulo e Minas Gerais. Entretanto, ainda segundo esta publicação, desde então, o segmento passou por uma expansão em território nacional. Nos anos de 1990, esses Estados respondiam por mais de 90\% da produção nacional de veículos. Em 2009, essa participação foi reduzida para cerca de $60 \%$. Outros Estados como Paraná, Rio Grande do Sul, Bahia e Rio de Janeiro passaram a absorver quase 30\% da produção veicular (BARROS e PEDRO, 2011).

A corrida entre os Estados para atrair as montadoras "[...] gerou o que convencionalmente se intitula por guerra fiscal [...] ou num termo mais amplo, poderia ser a guerra dos incentivos" (COELHO, 2012, p.64). O estabelecimento progressivo de novos grupos automobilísticos elevou a competição nesta indústria, o que, em médio prazo, reconfigurou a distribuição do mercado nacional de veículos. Nas palavras de Barros e Pedro (2011, p.192), na conjuntura de intensificação dos investimentos, novas características de concorrência se estabeleceram: "A entrada de novas montadoras, especialmente as chinesas e coreanas, pôde ser observada com um crescimento considerável. Uma das consequências dessa mudança estrutural". No entanto, apesar de sua expansão, frequentes oscilações têm caracterizado a instabilidade do setor automotivo na última década.

Segundo relatório prospectivo do setor automotivo elaborado pela ABDI (2011), o cenário surgido nos anos 2000 mostrou que o advento industrial indiano, chinês e de países do leste europeu tem representado uma ameaça aos investimentos no Brasil. Soma-se a esta situação os efeitos da crise econômica de 2008. De acordo com a publicação, este quadro econômico se configurou como um redefinidor dos processos automotivos, visto que empresas optaram pelo barateamento da produção por meio de terceirizações ou pela troca de fornecedores: 


\begin{abstract}
“[...] o processo de redução do número dos principais players do setor ainda está em curso e, com o advento da recente crise financeira de 2008, tende a se intensificar ainda mais. A tendência de se terceirizar processos é uma das respostas das empresas no sentido de reduzir a necessidade de maiores investimentos em determinados processos. Estas iniciativas por outro lado - não são isentas de novos riscos; questiona-se hoje até que ponto as principais fornecedoras das montadoras poderão se tornar elas mesmas montadoras e líderes da cadeia no futuro, uma vez que crescentemente influenciam os processos das montadoras" (ABDI, 2011, p.10)
\end{abstract}

As discussões sobre a reestruturação produtiva da indústria automotiva brasileira, conforme argumenta Garcia (2010, p.242), consideram o protagonismo da instabilidade econômica na "[...] descentralização do setor e na crise de antigas fábricas, como as do ABC paulista". Isso, segundo o autor, teve um efeito determinante no surgimento de novos debates sobre os arranjos flexíveis e desregulamentados que têm caracterizado os processos automotivos. Ao passo que diluíram a participação industrial para outros Estados brasileiros, as organizações do setor também conseguiram viabilizar configurações industriais mais convenientes para os seus interesses econômicos (NEVES, 2011). Esse olhar sobre as montadoras têm ocupado um espaço cada vez maior na construção da literatura sobre o setor automotivo em períodos mais recentes.

Segundo Franco (2009), por exemplo, o fluxo das empresas para localidades sem tradição na produção automotiva tem sido um dos principais indicadores da busca pelo barateamento da produção. Ao analisar a instalação de um grande grupo automotivo na Bahia, a autora alerta para o exercício de um poder assimétrico, estabelecido pelo capital estrangeiro frente à baixa representação trabalhista. Paralelamente, também foram discutidas outras questões político-fiscais obtidas pela empresa para viabilizar as suas imposições. O estudo feito em Camaçari, em síntese, exemplifica uma tendência dos grupos automotivos em um cenário de aparente estagnação do mercado automobilístico pós-crise (CASOTTI e GOLDENSTEIN, 2008). As mudanças nas estruturas de poder e a precarização do trabalho em processos cada vez mais flexíveis são alguns dos elementos que se sobressaem nesta nova fase do regime automotivo brasileiro.

\section{As mudanças nas estruturas de poder e a precarização do trabalho na indústria}

Para Carboni e Ehrlich (2013), diversos pesquisadores têm buscado, cada vez mais, medir os impactos das características organizacionais sobre os resultados gerados pelas empresas. A visão atual dos estudos acadêmicos, segundo estes autores, tem se distinguido da tradicional principalmente no que diz respeito às relações estabelecidas no trabalho. Nesta perspectiva, Carboni e Ehrlich (2013) estabeleceram uma comparação entre a fase do trabalho mecânico, e a etapa posterior, onde os relacionamentos interpessoais assumem um papel na estrutura de poder. Conforme suas palavras: "[...] a perspectiva do network assume que o comportamento dos indivíduos é influenciado pela estrutura onde [as pessoas] estão envolvidas" (CARBONI e EHRLICH, 2013, p.511-512).

As complexidades em relação ao trabalho decorreram, para Albornoz (2002), de influências ora filosóficas e ora sociais, com as quais o trabalhador contemporâneo passou a lidar em seu cotidiano. Na vertente filosófica, esta autora remontou estudos referentes à avaliação religiosa do trabalho, argumentando a respeito da influência histórica de alguns dos seus elementos para o triunfo capitalista. No lado social, a preocupação com a autovalorização se acentuou em virtude do surgimento das noções de status, de renda e de poder - exacerbados em um contexto da concorrência pelos postos de trabalho. A agregação de competências e qualificações, ainda segundo Albornoz (2002), está relacionada mais com a possibilidade de comparações entre os pares do que propriamente com as habilidades para a melhor execução técnica da função:

\footnotetext{
"O que preocupa o amigo que se informa sobre o trabalho do outro em geral é qual a renda que este consegue, qual o status que o emprego lhe confere, qual o poder que o seu trabalho lhe dá. Renda, status e poder substituem a preocupação e o cuidado de fazer bem alguma coisa que se sabe fazer." (ALBORNOZ, 2002, p.37)
}

Esta situação reforça para Faria e Meneghetti (2001) a tese de que as relações estabelecidas no local de trabalho têm cada vez mais adquirido uma dimensão social. Para estes autores, “[...] o sujeito passa a estabelecer padrões e a produzir um modo moral apto a corresponder à expectativa de uma aceitação social e de aliviar as repreensões" (FARIA 
e MENEGHETTI, 2001, p.02). Essa estrutura de poder estabelecida sobre bases ideológicas é assegurada por políticas organizacionais em torno das exigências de competências especiais, dos processos de planejamento e de metas mais desafiadoras. Desta forma, consolida-se a cooptação de traços subjetivos do trabalhador quando os investimentos do capital invertem os valores e tornam viáveis as atribuições que "[...] não são as dos sujeitos do trabalho, mas aquelas que a empresa requer destes sujeitos" (FARIA e RAMOS, 2012, p.11).

Essa perspectiva da dinâmica do poder também foi considerada por Carvalho (1998, p.13) ao assinalar que "[...] os estudos sobre o poder na teoria das organizações centralizam suas atenções sobre o quantum de desvio da estrutura formal". Nesse sentido, ainda que haja uma legitimidade da autoridade na estrutura organizacional, outras bases de poder podem ser identificadas no cotidiano nas empresas. Uma tipologia, segundo a autora, fundamentada ora na personalidade, ora nas alianças interpessoais, ou, ainda, na submissão a outrem devido ao poder econômico. A organização, assim, é a “[...] fonte de maior potencial na sociedade para que um indivíduo ou grupo alcance e exercite seu poder" (CARVALHO, 1998, p.15).

Segundo Pagès et al. (1987), esses mecanismos de poder são articulações das organizações em torno de processos de mediação, na tentativa de minimizar as contradições envolvidas no trabalho e assim enquadrar os indivíduos a uma postura de submissão consentida. Segundo os autores, o sistema capitalista de trabalho tem obtido êxito em função de uma subversão ideológica manifestada na deidificação das organizações: as empresas assumem o papel de patrocinadoras de status social para os seus membros e, em contrapartida, toleram erros e falhas da natureza humana. Com a metáfora, os autores articulam seus argumentos em termos de sacralização do capital e difusão da fé em um ambiente que, gradativamente, tem se tornado a própria concepção de mundo do trabalhador:

"É pelo fato de oferecer-lhes, além de satisfações propriamente materiais, satisfações de ordem ideológica e mesmo espirituais, que estes se reconhecem nela [organização], a ponto de se identificarem com a sua própria força. Estas satisfações são inerentes ao sistema de valores e crenças que a empresa propõe, sistema este que constitui ao mesmo tempo um quadro de referência coerente e ambicioso, uma concepção de mundo e uma moral de ação." (PAGÈS et al.,1987, p.76)
A retórica das organizações, segundo Druck e Franco (2011) e Antunes (2005), ao passo que garante a dominação, também levanta elementos que tratam da precarização do trabalho. Ao racionalizarem a produção em processos flexíveis, as empresas uniformizaram o trabalho repetitivo e localizado denominado de trabalho morto - e a construção desta conjuntura tem levado à informalidade, terceirizações, subcontratações e ao desemprego estrutural em larga escala. As tentativas dos gestores de tornarem as empresas cada vez mais modernas, "[...] parecem tornar mais intensos os níveis de degradação do trabalho" (ANTUNES, 2005, p.IV). Conforme comentou Leite (2004, p.239), “[...] o vínculo empregatício difunde-se em condições de trabalho e em relações de emprego mais deterioradas", visto que o avanço dos processos de terceirização tem feito diminuir a oferta de emprego na ponta mais virtuosa da cadeia e contribuído para a consolidação da instabilidade, precariedade e baixos salários.

A intensificação do trabalho precário tem afetado as condições psicológicas das pessoas e se manifestado como uma série de doenças psicossomáticas (ALVES, 2005). A intensificação destes sintomas, de acordo com o estudo de Patias, Belato e Olea (2008), tem sido ampliada, sobretudo, porque alternativas para reverter a lógica do capital têm se tornado cada vez mais escassas. Por meio de uma pesquisa qualitativa realizada com um grupo de trabalhadores, os autores concluíram que os métodos utilizados para a expansão do capital, antes viabilizada de maneira coercitiva, atualmente passam pela captura da subjetividade. Essa constatação partiu de depoimentos que mostraram que a "[...] característica da maioria é doar-se de corpo inteiro ao sistema, numa espécie de alienação que impede de ver para além da lógica do capital" (PATIAS, BELATO e OLEA, 2008, p.76). Esse fenômeno, com frequência, tem gerado dilemas na atual dinâmica do trabalho.

\section{Os mecanismos de controle sobre o trabalho na indústria}

De acordo com Hopfer e Faria (2006), os novos processos de controle ideológico passaram a explorar elementos como a competição interna, a individualidade e a identificação individual ao sucesso organizacional. Relações de trabalho fragmentadas, conforme comenta Albornoz (2002), geram alienação no indivíduo que não consegue perceber o resultado do seu trabalho para o produto final e, 
em visão abrangente, para o sentido de existência da organização. Ou, conforme argumenta Codo (2004), a alienação aparece num contexto em que o controle é pautado em objetivos obscuros e subjetivos, previstos em normas muitas vezes estranhas aos trabalhadores. Sendo assim, no "[...] trabalho, organizado na sociedade capitalista, ocorre uma ruptura, uma cisão, um divórcio entre o produto e o produtor" (CODO, 2004, p.19).

O controle sobre o trabalho, nestes termos, foi definido por Etzioni (1976) como uma variante simbólica - ou normativa-social - presente nas organizações. Outras categorias analíticas de controle também foram exploradas pelo autor: a física e a material - conforme apresentado na Figura 1. O controle desenvolvido por vias simbólicas descreve os meios por meio dos quais as pessoas são convencidas, diferentemente das recompensas estritamente materiais ou agressões físicas - que caracterizam os outros tipos de controle mencionados pelo autor. Esta categoria analisa a reação dos indivíduos a combinações de poder apoiadas em subjetividades sociais e culturais que permeiam organizações modernas.

Figura 1 - Evolução dos meios de controle organizacionais

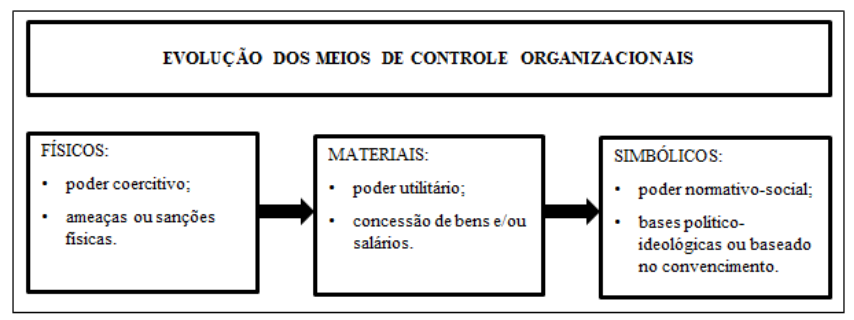

Fonte: Elaborado a partir de Etzioni (1976)

Nas palavras de Carvalho e Vieira (2007, p.61), "o tema controle [...] sempre esteve presente na sociologia das organizações dado que representa uma característica vital das organizações que compõem a sociedade moderna". Desempenhado pelos proprietários majoritários ou pelos diretores assalariados (BOLTANSKI e CHIAPELLO, 2009), a sua caracterização em períodos recentes tem sido diagnosticada por meio de mecanismos mais sofisticados demanipulaçãopsicológica ouporquestões relacionadas ao controle social das organizações sobre os trabalhadores (FARIA e BRUNING, 2013). Nas palavras de Faria e Ramos (2012, p.04), as diversas dimensões de controle sobre as relações de trabalho apresentaram-se subjetivamente "[...] em termos de insegurança, sofrimento psíquico, de esgotamento profissional, de perturbações psicossomáticas, depressões nervosas, entre outras".

A ligação entre os aspectos subjetivos e as práticas de controle, segundo mencionam Faria e Ramos (2012), tem sido assegurada por um discurso organizacional normalmente articulado de forma a se reduzir a crítica dos trabalhadores e, ao mesmo tempo, garantir um total comprometimento com as metas estabelecidas. O estudo de Backes (2012), realizado em uma empresa do setor industrial de grande porte, constatou que a subjetividade envolvida no controle sobre o trabalho tem refletido a insegurança quanto ao emprego nas organizações e o rompimento da cooperação, da solidariedade e de valores éticos entre seus membros. Esses mecanismos de coerção, de garantia de envolvimento e de responsabilização do trabalhador são apontados por Faria e Brunning (2013) como novos vetores dos debates sobre a temática do trabalho na indústria.

Os achados da pesquisa de Kindi (2013) sobre as experiências de trabalho na indústria - operada sob a lógica de capital flexível - enfatizaram a pluralidade de sentidos em torno das situações inscritas nas organizações. Segundo este autor, rivaliza com o sofrimento outras atitudes desenvolvidas pelos trabalhadores a fim de se adaptarem ao ambiente corporativo imposto pela dinâmica do capitalismo moderno:

"[...] existem diferentes situações de trabalho, e as pessoas podem, em certa medida, escolher. Existem situações diversas, empresas mais e menos éticas, empresas mais e menos competitivas, enfim, o mosaico do trabalho contemporâneo não é homogêneo nem coerente e sim contraditório e plural; gera desde um sofrimento acentuado até uma situação de adaptação significativa, sem excluir novas possibilidades" (KINDI, 2013, p.118-119)

O desafio, portanto, consiste em conciliar estes elementos com novos modelos de gestão que mitiguem sofrimentos em um ambiente de elevada instabilidade econômica (CIMBALISTA, 2007). Ao longo das discussões sobre as configurações do trabalho na indústria, foi possível verificar transformações marcadas por vínculos laborais menos perenes e por práticas de controle alinhadas ao discurso de alta performance. De acordo com os estudos apresentados, as configurações do trabalho 
têm se caracterizado por complexidades em estruturas de poder estabelecidas sobre bases ideológicas, além da produção de subjetividades de trabalhadores rendidos à lógica produtivista.

\section{Metodologia}

A presente pesquisa teve caráter qualitativo (STAKE, 2010). Os dados coletados por meio de entrevistas semiestruturadas tiveram um caráter longitudinal (VIEIRA, 2004) em um recorte temporal nos últimos cinco anos. Foram selecionados engenheiros de processos que compõem atualmente as equipes de trabalho temporárias no setor de processos industriais da montadora investigada. Para os fins deste estudo, a organização foi aqui chamada de ALFA. Tratase de um Grupo automotivo de origem europeia, com presença em 160 países e cerca de 200 mil trabalhadores em diferentes continentes (Institucional Grupo ALFA, 2013).

As entrevistas semiestruturadas seguiram um roteiro elaborado a partir do marco teórico escolhido. Foram definidas à priori as categorias de análise (GIL, 2008) a fim de organizar os dados levantados. Para critério de seleção dos sujeitos de pesquisa foi definido que os entrevistados tivessem participado de, pelo menos, um projeto de novo veículo entre os anos de 2008 e 2013. Assim, com base na fundamentação teórica da pesquisa, foram analisadas as seguintes categorias na pesquisa de campo: (1) os níveis de colaboração e cooperação entre os pares das equipes; (2) as práticas de controle sobre o trabalho, e (3) as relações de poder presentes nesta unidade da organização.

$\mathrm{O}$ agendamento das entrevistas foi iniciado em junho de 2014, se estendendo até o mês de setembro do mesmo ano. Os convites foram realizados por meio de contatos telefônicos ou por e-mails. Foram entrevistados doze profissionais de diferentes equipes de projetos. Todas as entrevistas ocorreram presencialmente. A experiência desta fase da pesquisa possibilitou o aprofundamento de questões essenciais à investigação dos fenômenos pesquisados.

Os procedimentos para a análise de conteúdo foram realizados de acordo com as etapas propostas por Bardin (1977): definição dos meios para coleta de dados; leitura do material selecionado; definição das unidades de análise; definição das categorias e subcategorias conforme a teoria adotada; e, execução da análise. Os resultados do levantamento de campo foram detalhados na seção a seguir.

\section{Resultados}

Os dados foram analisados a partir três elementos centrais: (a) os níveis de colaboração e cooperação entre os pares; (b) as práticas de controle sobre o trabalho e (c) as relações de poder no trabalho. Seguindo essas etapas foram então organizadas a seguir as falas dos engenheiros entrevistados na montadora ALFA.

\section{Os niveis de colaboração e cooperacão entre os pares nas equipes de projetos da ALFA}

Neste quesito a pesquisa de campo buscou avaliar como ocorre a delegação do trabalho nas equipes de projetos formadas a partir de 2008 (CARBONI e EHRLICH, 2013). Assim, de acordo com os sujeitos, o trabalho é desenvolvido de forma individualizada, limitado ao domínio técnico de cada região do veículo. Esse arranjo estrutural, numa das entrevistas, remeteu ao participante um desequilíbrio no convívio social do setor - definido pelo termo panelinha. De forma geral o trabalho foi descrito como sendo bastante individualizado:

\footnotetext{
"A equipe era composta de um piloto e quatro engenheiros de manufatura que eram separados por funções do carro." (E-4)
}

"O trabalho é desenvolvido de forma mais pessoal [...] O desenvolvimento do trabalho ele é de forma bem pessoal." (E-1)

"Eu acho que existia certa - vamos dizer assim - certa panelinha, né. Algumas panelinhas [...] Era individual. Era sempre sozinho mesmo. Cada um tinha o seu segmento." (E-3)

Quando indagados acerca do fluxo de trabalho entre os membros das equipes de projetos de novos veículos, os relatos forneceram elementos concernentes à fragmentação do sentimento de coletividade, e à mercantilização no cotidiano do trabalho. A busca por méritos pessoais e o corte de laços com a organização também apareceram nas entrevistas. O rompimento da solidariedade e de valores éticos entre os membros das equipes - verificado nas declarações dos sujeitos entrevistados - remontaram o estudo de Backes (2012) sobre a subjetividade presente nos conflitos entre trabalhadores nos períodos de transformações organizacionais: 
"Questionando o atual chefe sobre isso, ele disse que 'cada um deve fazer por si só' [...] O cara passou uma apresentação com 150 a 200 slides em francês e depois bateu a mão no meu ombro e disse: 'Depois você dá uma olhada que é importante' [...] Ele bateu nas minhas costas e disse: 'Agora é contigo, entendeu?” “(E-8)

"Eu vejo que tem gente dentro da equipe com problema de relacionamento um com outro [...] A grande parte dos problemas acontecem por interesses pessoais mesmo." (E-6)

"Existe uma cultura de rivalidade, de apontar o dedo, de falar quem está errado. E isso cria um ambiente péssimo.” (E-12)

A reprodução de condutas profissionais convenientes ao ambiente das organizações foi mencionada por Kindi (2013) ao discutir as atitudes dos indivíduos a fim de se adaptarem à lógica do capital flexível inserida na dinâmica do capitalismo moderno. Este elemento organizacional apareceu na fala de um dos entrevistados quando observa na organização ALFA a construção de um modelo profissional a ser seguido nos relacionamentos interpessoais. $\mathrm{Na}$ opinião do participante, há uma contradição entre o comportamento comumente prescrito e aquele observado no dia-a-dia da organização:

"É difícil lidar com pessoas, trabalhar com pessoas [...] Até
mesmo quando você vê uma chamada de emprego, eles criam
um modelo, um perfil de pessoa que é o mesmo para todas as
empresas [risos] E é o que não acontece [...] Esses modelos
que as pessoas criam que, na verdade, são mentirosos." (E-6)

A padronização do comportamento dos indivíduos nas organizações tem sido explicada como um artifício para associarem o sucesso pessoal ao organizacional (HOPFER e FARIA, 2006). Segundo Carvalho e Vieira (2007) isso é um sintoma de um controle ideológico subjacente à lógica estabelecida pelo capital. Os aspectos sociais referentes à relação interpessoal entre os pares das equipes problematizaram questões como o rompimento do senso de solidariedade no setor de processos industriais da ALFA. Com base nos depoimentos também foi possível levantar outros aspectos também pertinentes, como a resistência em fornecer informações, os conflitos de interesses e o individualismo na condução das atividades diárias.

\section{As práticas de controle sobre o trabalho no setor de processos industriais da montadora}

A questão das práticas de controle ampliou o estudo na direção vertical dos relacionamentos estabelecidos na empresa. A investigação desse elemento buscou obter informações acerca do escalonamento das atividades previstas no plano de gestão de projetos usado na organização ALFA. Foi feito um questionamento aos membros das equipes de projetos sobre como é realizada a mensuração da produtividade nos processos industriais, e também como são cobrados os resultados dos trabalhos desenvolvidos. De acordo com os depoimentos dos engenheiros, esse acompanhamento é realizado de forma cumulativa ao longo do projeto, e registrado por meio de reuniões com as hierarquias, onde são apresentados os relatórios e indicadores:

"O tempo do projeto e ao longo ele era dividido em fases, e durante cada fase você tinha uma porcentagem que você tinha que alcançar de validações do processo.” (E-2)

\footnotetext{
"As pessoas têm determinadas atribuições controladas alguns indicadores. [...] Você é responsável por fechar aquele indicador e apresentar diretamente para a sua hierarquia." (E9)
}

"São feitas as reuniões diárias e nessas reuniões são abordados todos os temas que estão em curso: os resultados, os prazos, as ações...” (E-11)

Os objetivos e metas, nas palavras dos entrevistados, mudam bastante em virtude do cenário de constantes mudanças da organização ALFA. Por se tratar de um sistema de controle rigoroso e pautado em resultados desafiadores (FARIA e RAMOS, 2012), são detectados nesta empresa os mecanismos de garantia envolvimento dos trabalhadores. O compromisso incondicional com os objetivos da empresa é assegurado por diretrizes de ordem. Nas respostas dos participantes esse sistema tem semelhança com o controle exercido pelas forças armadas. Os detalhes fornecidos por um dos entrevistados inclui a coerção (ETZIONI, 1976) - definida pela expressão cantinho da disciplina - como uma prática já realizada no setor para dirimir desvios:

“[...] acaba sendo um pouco - não é militarizada, não é essa palavra não -, mas uma diretriz de ordem existe e tem que ser cumprida, né. [...] Ela é muito bem definida nesse sentido, 
né, e as funções, as tarefas, estão muito bem definidas e controladas com muito rigor." (E-1)

\begin{abstract}
"Os objetivos mudavam muito ao longo do tempo [...] Fazia um regime meio que opressor assim, entende? [...] Então você se sentia meio coagido pra fazer aquilo de qualquer forma [...] Então isso acaba sendo muito ruim porque eu me sentia mal" (E-2)
\end{abstract}

"[...] nesse caso me chamaram para um lugar que eles chamam de 'cantinho da disciplina' [pausa] E gera um conflito porque eles não conseguem definir prioridades.” (E-8)

A partir dos relatos foi possível identificar, desta forma, a insatisfação dos membros das equipes em estarem sujeitos a situações onde são constantemente coagidos ou pressionados; e isso, conforme argumenta Antunes (2005), tem acarretado precarização para a disposição corpo-mente dos trabalhadores. Nas palavras de outros engenheiros, além da dificuldade em atingir as metas, existe também a impressão de que os resultados são subjetivos e inatingíveis, gerando assim: (a) esgotamento profissional (FARIA e RAMOS, 2012) e (b) desvinculação do indivíduo que não compreende a sua contribuição para o produto final da organização (ALBORNOZ, 2002):

“Às vezes vocêtem objetivos que são praticamenteimpossíveis, que você já sabe que não serão atingidos [...] Dizem que esses objetivos servem para o seu desenvolvimento profissional, que pra mim até hoje nunca valeu de droga nenhuma." (E-6)

"Muitas vezes as equipes trabalham sem saber onde é que é o norte [...] Se você trabalha sem conhecer o objetivo, fica muito difícil de executar um bom trabalho." (E-5)

As declarações acerca das práticas de controle sobre os resultados remeteram, portanto, ao sistema de gerenciamento de projetos em fases cumulativas, com indicadores apresentados em reuniões periódicas. Foi possível estabelecer uma ligação entre as formas como esse controle é estabelecido no setor de processos industriais com o estudo de Castro (1995): a garantia de comprometimento é viabilizada por meio do acúmulo de responsabilidades. A coerção dos engenheiros de processo é realizada de forma sofisticada por meio de pressão psicológica por resultados por vezes subjetivos e, na visão dos entrevistados, quase sempre inatingíveis. Ao mencionarem termos militares, os membros das equipes transmitem o rigor e as diretrizes de ordem que caracterizam o controle por resultados na montadora.

\section{A estrutura de poder no setor de processos industriais na montadora ALFA}

A análise dos achados considera, neste caso, a definição do poder manipulativo assinalado por Boltanski e Chiapello (2009): praticado por gerentes e diretores assalariados sob a égide do espírito do capitalismo. Ou conforme comentam Faria e Ramos (2012), uma coerção não mais estabelecida por meio da legitimidade do cargo, e sim a partir de bases ideológicas consolidadas sobre o trabalhador rendido ao ideal capitalista. $O$ trecho destacado a seguir resume o pensamento dominante e encontrado com recorrência entre os entrevistados:

"Então a gente tem que estar sempre preparado, se qualificando cada vez mais, porque o mercado está muito competitivo, tem cada vez menos vagas, e cada vez mais candidatos. Então todo mundo tem que se qualificar para conseguir alguma coisa, se não vai ficar pra trás.” (E-7)

A postura de submissão consentida definida por Pagès et al. (1987) é garantida por um poder financeiro que a organização ALFA exerce sobre os indivíduos em tempos de escassez de novas vagas. Igualmente, os entrevistados assinalam a capacidade de persuasão que a empresa obtém pelo fato de ser reconhecida como a provedora dos recursos materiais almejados pelos trabalhadores - que eventualmente possuiriam menor renda em outras funções. Esse status obtido pela organização foi analisado por Pagès et al. (1987) como um fenômeno chamado de deidificação, em que os as pessoas se convencem de uma total dependência financeira dos vínculos de trabalho - conforme foi relatado em uma das entrevistas:

"Eles procuram um cara com um perfil tipo que tem família, que necessita daquele emprego, entende? Existe um trabalho de convencimento da pessoa, de persuasão para que as pessoas abracem aquilo ali como se fosse a sua casa." (E-4)

"A gente sabe que o braço financeiro mais forte acaba sendo a empresa. O emprego é uma necessidade de sustento [...] Hoje a gente vê que algumas condições a empresa determina e ninguém discute isso." (E-9)

Outras respostas fornecidas revelaram a captura da subjetividade (Patias, Belato e Olea, 2008) dos indivíduos em suas experiências de trabalho junto às hierarquias do setor de processos industriais. Os depoimentos descreveram a utilização de recursos 
pela estrutura de poder que se sobrepõem ao exercício técnico da função. Esse tipo de relacionamento vertical no setor é caracterizado pelos engenheiros como a causa de estresse e de desapontamentos, principalmente por ser um sintoma da frequente manipulação dos resultados (FARIA e BRUNING, 2013). Além de relatarem o fato de que parte considerável das prioridades é circunstancial ou negociada segundo interesses. Nas respostas apareceram com recorrência termos associados à predominância do viés político sobre o saber fazer das pessoas:

"Mesmo você sabendo qual era a prioridade, não necessariamente era o que você estava vendo, mas sim o que mandam para você fazer [...] Aí você vê a influência da política dentro da organização [...] Isso estressa porque você tem que dar conta disso e do que é essencial.” (E-2)

"[...] A organização se torna um âmbito muito político [...] Na maioria das questões, o trabalho em si não é expressivo." $(\mathrm{E}-1)$

"[...] Hoje você vê muito a questão da afinidade. Ou seja, tem uma questão que não basta você ser apenas um bom profissional." (E-9)

A questão do poder também foi identificada nos depoimentos a partir de outro elemento, referente à influência da montadora sobre os fornecedores. Segundo Sacomano, Truzzi e Kirschbaum (2013) essa tem sido uma modalidade de relacionamento comum em novos arranjos produtivos, onde há uma presença cada vez maior de fornecedores condôminos. Um dos exemplos extraídos das entrevistas diz respeito aos privilégios obtidos por membros ALFA em trabalhos realizados junto a parceiros técnicos durante os projetos:

"Já vi fornecedores pagando almoço para funcionários da empresa... Isso chega a ser comum lá.” (E-8)

A estrutura de poder estabelecida no setor de processos industriais, nos termos mencionados pelos entrevistados, acaba sendo potencializada pela duplicidade de coordenações da estrutura matricial. O conflito de prioridades entre as demandas de projeto e de veículos produzidos em série influencia na tomada de decisões por vias políticas ou circunstanciais. Outro elemento indicado nas entrevistas foi o poder financeiro da empresa, que adquire proporções ainda maiores num cenário de instabilidade no emprego. $\mathrm{O}$ arranjo estrutural do setor de processos industriais, mantido por contratos temporários, também parece favorecer a submissão dos indivíduos a tais condições de trabalho.

Quadro 2 - Síntese dos resultados coletados na montadora ALFA

\begin{tabular}{|c|c|c|}
\hline $\begin{array}{c}\text { Níveis de } \\
\text { colaboração } \\
\text { e cooperação } \\
\text { entre os pares }\end{array}$ & $\begin{array}{c}\text { Prática de } \\
\text { controle sobre o } \\
\text { trabalho }\end{array}$ & $\begin{array}{c}\text { Relações de } \\
\text { poder no } \\
\text { trabalho }\end{array}$ \\
\hline $\begin{array}{c}\text { Trabalho } \\
\text { desenvolvido de } \\
\text { forma pessoal }\end{array}$ & $\begin{array}{c}\text { Indicadores de } \\
\text { controle dos } \\
\text { resultados }\end{array}$ & $\begin{array}{c}\text { Predominância } \\
\text { do lado político } \\
\text { sobre o técnico }\end{array}$ \\
\hline $\begin{array}{c}\text { Formação de } \\
\text { "panelinhas" no } \\
\text { setor }\end{array}$ & $\begin{array}{c}\text { Objetivos } \\
\text { conflitantes e } \\
\text { subjetivos }\end{array}$ & $\begin{array}{c}\text { Poder } \\
\text { sobre babelecido } \\
\text { ideológicas }\end{array}$ \\
\hline $\begin{array}{c}\text { Conflitos } \\
\text { interpessoais nas } \\
\text { equipes }\end{array}$ & $\begin{array}{c}\text { Uso do "Cantinho } \\
\text { da disciplina" }\end{array}$ & $\begin{array}{c}\text { Poder financeiro } \\
\text { da empresa }\end{array}$ \\
\hline $\begin{array}{c}\text { Prescrição de } \\
\text { modelo de } \\
\text { profissional }\end{array}$ & $\begin{array}{c}\text { Militarização do } \\
\text { trabalho no setor }\end{array}$ & $\begin{array}{c}\text { Relação de poder } \\
\text { entre montadora } \\
\text { e fornecedores }\end{array}$ \\
\hline
\end{tabular}

Fonte: Elaborado pelo autor

A análise dos dados a partir a teoria permitiu relacionar elementos do convívio social entre os pares das equipes de projetos, como também destes com os seus superiores. Em síntese, os achados obtidos junto ao setor de processos industriais da montadora ALFA revelaram as seguintes questões principais:

i. O arranjo estrutural adotado pelo setor de processos industriais tem potencializado a quebra da coletividade entre os engenheiros das equipes de projetos. Essa condição vai ao encontro de estudos mencionados no artigo sobre as mudanças vividas pelos trabalhadores em períodos de transformações organizacionais; inclusive escassez de novas vagas na indústria.

ii. Pelos relatos de campo também foi possível verificar que o controle nessa estrutura é rigoroso, mas obscuro. Esse elemento reforçou a tese de autores que abordaram a temática 
da alienação - no sentido de representar um distanciamento entre trabalho e sentido de existência das organizações. Igualmente, o controle de desempenho é praticado por vias mais ideológicas, o que acarreta a produção de subjetividades por parte dos trabalhadores.

iii. Neste contexto, a dinâmica de poder tem se estabelecido de duas formas principais: a financeira e a política. Essas dimensões foram abordadas na literatura como um fenômeno chamado de deidificação das firmas. Desta forma, a coerção é assegurada, muitas vezes, de modo circunstancial ou negociado. Essa situação foi definida pelos entrevistados como causa permanente de estresse e de desapontamento no setor de processos industriais.

As relações de poder e controle na montadora ALFA passaram, portanto, por transformações substanciais nos últimos anos. $\mathrm{O}$ arranjo estrutural por equipes de projetos no setor de processos industriais acabou acentuando o sentimento de instabilidade no emprego e, em virtude disto, a impressão de que as condições de trabalho tornaram-se mais precárias. A partir material coletado, o estudo torna possível assim reunir dados que suscitam discussões sobre as contradições existentes entre as configurações de trabalho cada vez mais complexas e a degradação das condições de vida dos trabalhadores.

\section{Conclusão}

A partir da discussão teórica levantada e dos dados obtidos na pesquisa de campo conclui-se que a atual configuração estrutural da montadora ALFA tem produzido impactos danosos para os engenheiros de processos - sobretudo no período correspondente à reestruturação produtiva da montadora investigada. Sendo assim, as relações de poder e controle presentes nos vínculos de trabalho têm se manifestado, especialmente, por meio de contradições entre a busca por uma alta performance em produtividade e a precarização das condições de vida dos trabalhadores.

Quantoàs relações estabelecidas nas equipes deprojetos do setor de processos industriais, há uma intensificação de conflitos interpessoais que, progressivamente, tem comprometido a coletividade entre os pares funcionais. Isso tem ocorrido devido a um discurso da hierarquia no qual se incitam a competição pela meritocracia e a associação do rendimento produtivo individual ao sucesso organizacional. A combinação desses elementos foram os subsídios de uma análise interpretativa sobre como são aplicadas as práticas de controle sobre o trabalho e o exercício de poder por parte dos gerentes médios.

No que diz respeito às relações de poder no campo investigado, essas foram definidas como subjetivas, circunstanciais ou políticas - sintomas da influência permanente do status e da afinidade interpessoal sobre o desempenho técnico da função. Nesse sentido, a postura de submissão dos trabalhadores apareceu como uma consequência da dependência financeira em relação à organização. A visão das pessoas entrevistadas é de que a empresa representa o lado mais forte quanto à imposição das condições de trabalho; situação esta potencializada em virtude da escassez de novas vagas na indústria.

Já o controle sobre a produtividade assumiu termos como militarização e diretriz de ordem -citados pelos engenheiros ao se referirem à coerção a que são submetidos. Ao relatarem suas experiências, os sujeitos admitiram internalizar elevado grau de estresse e desapontamento. Esse quadro apareceu associado aos frequentes questionamentos em relação aos objetivos do trabalho - classificados como inatingíveis -, que parecem reforçar o distanciamento entre o trabalho desenvolvido nas equipes de projetos e o sentido de existência da empresa.

As mudanças no setor automotivo, advindas, sobretudo, da fragmentação da concorrência e da volatilidade do ciclo de vida dos veículos, têm representado portanto um novo desafio para pesquisadores no âmbito da Administração. Existe, assim, uma lacuna a ser identificada nas discussões sobre novos arranjos estruturais que, ao mesmo tempo, atendam aos objetivos das empresas e sejam menos danosos do ponto de vista dos trabalhadores. Nesse sentido, o artigo pretende sustentar uma reflexão sobre a suposta impossibilidade de se remediar a precarização do trabalho, inclusive em segmentos que mercantilizam a dita cultura da alta performance.

Sugere-se, como perspectivas futuras nesta área de estudo, a investigação a nível operacional da empresa ALFA. Isso poderia levantar novas discussões sobre como são desenvolvidas as formas de controle da produtividade em outras instâncias da empresa, bem como a estrutura de poder associada a tal 
prática organizacional. Assim, também seria possível compreender as novas expectativas dos profissionais que têm convivido de forma mais direta com as mudanças laborais nos processos automotivos.

\section{Referências Bỉbliográficas}

ABDI. O Núcleo Tecnológico da Indústria Brasileira. In. DE NEGRI, João Alberto; LEMOS, Mauro Borges (Org.). Brasília: IPEA-FINEP-ABDI, 2011.

ALBORNOZ, Suzana. O que é trabalho. 6 ed. São Paulo: Brasiliense, 2002.

ALVES, G. Trabalho, corpo e subjetividade: toyotismo e formas de precariedade no capitalismo global. Trab. educ. saúde, Rio de Janeiro, v. 3, n. 2, set. 2005.

ALVES FILHO, A. G.; NOGUEIRA, E.; BENTO, P. E. G. Análise das estratégias de produção de seis montadoras de motores para automóveis. Gest. Prod., São Carlos, v. 18, n. 3, p.603-618, 2011.

ANTUNES, R. L. C. O caracol e sua concha: ensaios sobre a nova morfologia do trabalho. São Paulo: Boitempo, 2005.

ARBIX, G. Políticas do desperdício e assimetria entre público e privado na indústria automobilística Políticas do desperdício e assimetria entre público e privado na indústria automobilística brasileira. Rev. bras. Ci. Soc., São Paulo, v. 17, n. 48, p.109-129, 2002.

BACKES, A. L. Trabalho e subjetividade: sofrimento psíquico em contexto de mudanças organizacionais.

Gestão e Sociedade, v. 6, n. 14, p. 117-138, 2012.

BARDIN, L. Análise de conteúdo. Lisboa: Edições 70, 1977.

BARROS, D. C.; PEDRO, L. S. As mudanças estruturais do setor automotivo, os impactos da crise e as perspectivas para o Brasil. BNDES Setorial, n. 34. Rio de Janeiro: BNDES, 2011.

BOLTANSKI, L.; CHIAPELLO, E. O novo espírito do capitalismo. São Paulo. Martins Fontes. 2009.

BOTELHO, A. Reestruturação produtiva e produção do espaço. O caso da indústria automobilística instalada no Brasil. Revista do departamento de Geografia, São Paulo, v. 15, p.55-64, 2002.

CARBONI, I; EHRLICH, K. The Effect of
Relational and Team Characteristics on Individual Performance: A Social Network Perspective. Human Resource Management, v. 52, n. 4, p.511-535, 2013.

\section{CASOTTI, B. P.; GOLDENSTEIN, M. Panorama} do setor automotivo: as mudanças estruturais da indústria e as perspectivas para o Brasil. BNDES Setorial, Rio de Janeiro, n.28, p.147-188, 2008.

CASTRO, N. A. de. Modernização e trabalho no complexo automotivo brasileiro: reestruturação industrial ou japanização de ocasião? In: (Org.). A Máquina e o equilibrista: inovações na indústria automobilística brasileira. Rio de Janeiro: Paz e Terra, 1995.

CARVAlHO, C. A. Poder, conflito e controle nas organizações modernas. - Maceió : EDUFAL, 1998.

; VIEIRA, M. M. F. O poder

nas organizações. São Paulo: Thomson Learning, 2007.

CIMBALISTA, S. Sofrimento: O Sentido adverso das condições de trabalho sob o Sistema de Produção Flexível. Univ. Psychol., Bogotá, v. 6, n. 1, p.69-78, 2007.

CODO, W. O que é alienação. 3. ed. São Paulo : Brasiliense, 2004.

COELHO, A. L. C. O Quinto Ciclo da Guerra Fiscal e a Nova Indústria Automobilística Brasileira. RDE - Revista de Desenvolvimento Econômico, Salvador, Ano XIV, n. 26, 2012.

DRUCK, G; FRANCO, T. Trabalho e precarização social. Cad. CRH [online]. v. 24, n.spe1, p. 09-13, 2011.

ETZIONI, A. Organizações modernas. 5. ed. São Paulo : Pioneira, 1976.

FARIA, J. H.; MENEGHETTI, F. K. O sequestro da subjetividade e as novas formas de controle psicológico no trabalho: Uma abordagem crítica ao modelo toyotista de produção. Anais... 25 $5^{\circ}$ Encontro da Associação Nacional de Pós-graduação e Pesquisa em Administração [1 CD-ROM]. Campinas, SP: ANPAD, 2001.

FARIA, J. H.; RAMOS, C. L. Poder e ideologia em um programa de gestão por competências: análise crítica do modelo corporativo em uma indústria multinacional de energia. Anais... $36^{\circ}$ Encontro da Associação Nacional de Pós-graduação e Pesquisa 
em Administração [1 CD-ROM]. Rio de Janeiro, RJ: ANPAD, 2012.

FARIA, J. H.; BRUNING, C. O problema dos mais novos: um estudo de caso sobre o conflito de gerações na linha de produção de uma montadora automotiva da Região Metropolitana de Curitiba.

Revista Eletrônica de Ciência Administrativa, v. 12, n. 3, p. 353-365, 2013.

GARCIA, S. R. Global agents and the local level: the Gravataí automotive complex. Sociologias, Porto Alegre, v. 5, Selected Edition, 2010.

GIL, A. C. Métodos e técnicas de pesquisa social. 6. ed. - São Paulo : Atlas, 2008.

GRUPO AUTOMOTIVO ALFA, 2013.

Departamento de Recursos Humanos. Relatório.

Rio de Janeiro. Acessado em: 30 jan. 2014.

HOPFER, K. R; FARIA, J. H. de. Controle por resultados no local de trabalho: dissonâncias entre o prescrito e o real. RAE electron., São Paulo, v. 5, n. 1, 2006.

INSTITUCIONAL GRUPO ALFA, 2013.

Disponível em: <www.psapeugeotcitroen.com.br>. Acesso em: 28 jan. 2014.

KINDI, E. Os sentidos de experiências de trabalho em tempos de flexibilização. 2013. Dissertação (Mestrado em Psicologia Social) Instituto de Psicologia, Universidade de São Paulo, São Paulo, 2013.

LEITE, M. P. Tecendo a precarização: trabalho a domicílio e estratégias sindicais na indústria de confecção em São Paulo. Trab. educ. saúde, Rio de Janeiro, v. 2, n. 1, 2004.

NEVES, M. A. Trabalho atípico. In: CATTANI, A. D.; HOLZMANN, L. (Orgs.). Dicionário de trabalho e tecnologia. Porto Alegre: Editora Zouk, p. 440-444, 2011.

PAGÈS et al. O poder das organizações: a dominação das multinacionais sobre os indivíduos / Max Pagès ... (et al.) ; tradução Maria Cecília Pereira Tavares, Sonia Simas Favatti ; revisão técnica Pedro Anibal Drago. -- São Paulo: Atlas, 1987.

PATIAS, T. Z.; BELATO, D.; OLEA, P. M.

Percepções de um grupo de trabalhadores sobre as transformações no mundo do trabalho. Revista Pretexto, v. 9, n. 1, art. 4, p.63-80, 2008.

PINTO, G. A. O Toyotismo e a mercantilização do trabalho na indústria automotiva do Brasil. Cad.
CRH, Salvador, v. 25, n. 66, p.535-552, 2012.

RODRIGUES, I. J. Um laboratório das relações de trabalho: o ABC paulista nos anos 90. Tempo soc., São Paulo, v. 14, n. 1, 2002.

SACOMANO NETO, M.; TRUZZI, O. M. S.; KIRSCHBAUM, C. Isomorfismo e controle institucional em uma planta modular da indústria automobilística. Revista Brasileira de Gestão de Negócios, v. 15, n. 49, p.524-544, 2013.

STAKE, R. E. Qualitative research: studying how things work. New York, NY. The Guilford Press, 2010

TENORIO, F. G. A unidade dos contrários: fordismo e pós-fordismo. Rev. Adm. Pública, Rio de Janeiro, v. 45, n. 4, p.1141-1172, 2011.

VIEIRA, M. M. F. Por uma boa pesquisa (qualitativa) em Administração. In: VIEIRA, Marcelo Milano Falcão; Zouain, Deborah Moraes. Pesquisa qualitativa em administração. FGV Editora, 2004. 